A) Check for updates

Cite this: DOI: 10.1039/d0mt00034e

Received 8th February 2020,

Accepted 27th March 2020

DOI: $10.1039 / \mathrm{d} 0 \mathrm{mt} 00034 \mathrm{e}$

rsc.li/metallomics

\section{Characterization of the Fe metalloproteome of a ubiquitous marine heterotroph, Pseudoalteromonas (BB2-AT2): multiple bacterioferritin copies enable significant Fe storage $\dagger$}

\author{
Michael G. Mazzotta, (D) * Matthew R. Mcllvin (D) and Mak A. Saito (D) *
}

Fe is a critical nutrient to the marine biological pump, which is the process that exports photosynthetically fixed carbon in the upper ocean to the deep ocean. Fe limitation controls photosynthetic activity in major regions of the oceans, and the subsequent degradation of exported photosynthetic material is facilitated particularly by marine heterotrophic bacteria. Despite their importance in the carbon cycle and the scarcity of $\mathrm{Fe}$ in seawater, the Fe requirements, storage and cytosolic utilization of these marine heterotrophs has been less studied. Here, we characterized the Fe metallome of Pseudoalteromonas (BB2-AT2). We found that with two copies of bacterioferritin (Bfr), Pseudoalteromonas possesses substantial capacity for luxury uptake of Fe. Fe: $\mathrm{C}$ in the whole cell metallome was estimated (assuming C:P stoichiometry $\sim 51: 1$ ) to be between $\sim 83 \mu \mathrm{mol}: \mathrm{mol} \mathrm{Fe:C,} \sim 11$ fold higher than prior marine bacteria surveys. Under these replete conditions, other major cytosolic Fe-associated proteins were observed including superoxide dismutase (SodA; with other metal SOD isoforms absent under Fe replete conditions) and catalase (KatG) involved in reactive oxygen stress mitigation and aconitase (AcnB), succinate dehydrogenase (FrdB) and cytochromes (QcrA and Cyt1) involved in respiration. With the aid of singular value decomposition (SVD), we were able to computationally attribute peaks within the metallome to specific metalloprotein contributors. A putative $\mathrm{Fe}$ complex TonB transporter associated with the closely related Alteromonas bacterium was found to be abundant within the Pacific Ocean mesopelagic environment. Despite the extreme scarcity of $\mathrm{Fe}$ in seawater, the marine heterotroph Pseudoalteromonas has expansive Fe storage capacity and utilization strategies, implying that within detritus and sinking particles environments, there is significant opportunity for Fe acquisition. Together these results imply an evolved dedication of marine Pseudoalteromonas to maintaining an Fe metalloproteome, likely due to its dependence on Fe-based respiratory metabolism.

Significance to metallomics

Fe is an essential nutrient to marine heterotrophic bacteria that catalyze the decay of biogenic particles derived from phototrophic organisms. Pseudoalteromonas associates with detrital matter and marine snow, making it an ideal model microbe for exploring biochemistries relevant to carbon export. We have used metalloproteomics to identify the Fe reservoirs within this bacterium, which includes two active copies of the bacterioferritin protein, enabling significant Fe storage, and contributing to $\sim 72 \%$ of the Fe metallome. Incorporation of Fe into reactive oxygen stress mitigation and respiratory enzymes was also identified. Together, our results indicate the substantial storage capacity for Fe within this marine heterotrophic bacterium, despite the scarcity of Fe in seawater.

\section{Introduction}

Fe is an essential element to nearly all living organisms and limited in availability within the surface ocean due to the low

Marine Chemistry and Geochemistry Department, Woods Hole Oceanographic Institution, Woods Hole, Massachusetts, USA. E-mail: mgm@whoi.edu, msaito@whoi.edu

$\dagger$ Electronic supplementary information (ESI) available. See DOI: 10.1039/d0mt00034e solubility of $\mathrm{Fe}^{3+}$ in oxic seawater. ${ }^{1}$ Field incubation experiments have demonstrated that Fe limitation controls primary productivity in major regions of the oceans and in turn can affect the biological pump of carbon from the surface to the deep ocean..$^{2-5}$ This biological pump removes carbon through the fixation of $\mathrm{CO}_{2}$ by marine phototrophs, many of which utilize sophisticated metalloproteins throughout their metabolism. The biogenic particles that result from these phototrophic organisms are then consumed by microbially mediated degradation and 
zooplanktonic members of the community, also facilitated by metalloenzymes, representing an additional and valuable component of carbon-cycling within the marine environment. ${ }^{6,7}$ Thus, understanding the microbial metalloenzymes that mediate these processes facilitates understanding global biogeochemical changes. $^{8}$

Mechanisms for sequestering scarce bioactive trace metals, such as Fe, are critical to carbon cycling. ${ }^{9,10}$ Fe limitation is known to be important in controlling photosynthetic activity in the epipelagic zone $(0-200 \mathrm{~m})$, but there is increasing interest in the challenges in Fe nutrition faced by heterotrophic bacteria in the epipelagic and mesopelagic zones (200-1000 m), where Fe sources can vary including, dust, sinking particles, coastal sediment and hydrothermal vents. ${ }^{2,11-13}$ Fe serves roles in catalysis and electron transport within autotrophic and heterotrophic microbes, however the partitioning of these trace metals into their respective metalloenzymes is a question outstanding. ${ }^{14,15}$ Notably, pelagic heterotrophic bacteria require greater quotas of Fe per unit biomass in comparison to phytoplankton. ${ }^{16-20}$ The strategies of heterotrophic Fe uptake have been probed at the molecular level, ascertaining the structural details of organismspecific siderophores, ${ }^{21-27}$ and additionally at the biological level in an effort to understand $\mathrm{Fe}$ transport processes and taxonomic specificity. ${ }^{28-31}$ Despite the understandings gained on the mechanisms of Fe uptake and transport, the marine heterotrophic bacterial cellular metallome remains underexplored.

Pseudoalteromonas is a ubiquitous marine heterotroph, a genus that was proposed within the $\gamma$-subgroup of the Proteobacteria class, isolated in both the open ocean and coastal marine environment. $^{32}$ Numerous metagenomic-transcriptomic studies have characterized the cosmopolitan nature of this bacterium from global sampling campaigns. ${ }^{33,34}$ Observed as a constituent of phytoplankton blooms and sinking particles in field and mesocosm experiments, ${ }^{35-38}$ these organisms have been characterized as fast-growing copiotrophic bacteria adapted to organic-rich conditions, in contrast to oligotrophic microbes that grow under low substrate concentration with higher affinities for specific carbon substrates. ${ }^{39,40}$ Alteromonadales have been isolated from the surface of particles within sediment traps and are often associated with detritus and other marine snow sources, making them an ideal model microbe for exploring biochemistries relevant to carbon export. ${ }^{41,42}$ Understanding how trace metals influence Pseudoalteromonas, including their organic matter degradation capabilities and their metalloenzyme reactivity and metal selectivity, is useful in understanding the biogeochemical constraints on these microbes. ${ }^{43-45}$

This study examines the connections between the biogeochemistry of marine heterotrophic bacteria and Fe through the investigation of the cellular metalloproteome of Pseudoalteromonas. This method employs two dimensions of chemical separation using anion exchange and size exclusion chromatography on cytosolic metalloproteins after native (non-denaturing) lysis methods (Fig. 1). ${ }^{46-48}$ The resulting 384 sub-samples of the purified lysate were characterized by proteomics and inductively coupled plasma-mass spectrometry (ICP-MS) to identify protein and elemental distributions within each sample, which together elucidates the major soluble metalloprotein reservoirs. This manuscript focuses on the Fe metallome of Pseudoalteromonas, while a future manuscript will describe the additional metals.

\section{Experimental}

\section{Culturing of Pseudoalteromonas}

Marine broth medium was prepared by microwave sterilization ${ }^{49}$ of $800 \mathrm{~mL}$ of $0.2 \mu \mathrm{m}$-filtered Vineyard Sound seawater with the addition of $0.2 \mu \mathrm{m}$-filter-sterilized solutions of $4 \mathrm{~g}$ peptone (Fisher Scientific) and $0.8 \mathrm{~g}$ yeast extract (BD Difco). Marine agar plates were prepared with the same composition as that of the marine broth described herein, with the inclusion of $12 \mathrm{~g}$ granulated agar (Fisher Scientific) and sterilization achieved by autoclaving for 30 min. Cultures of Pseudoalteromonas sp. BB2-AT2 were revived from a $20 \%$ glycerol stock of BB2-AT2 (provided by Kay Bidle, Rutgers University) and used to inoculate approximately $1 \mathrm{~mL}$ of marine broth. The inoculated solution was allowed to incubate at

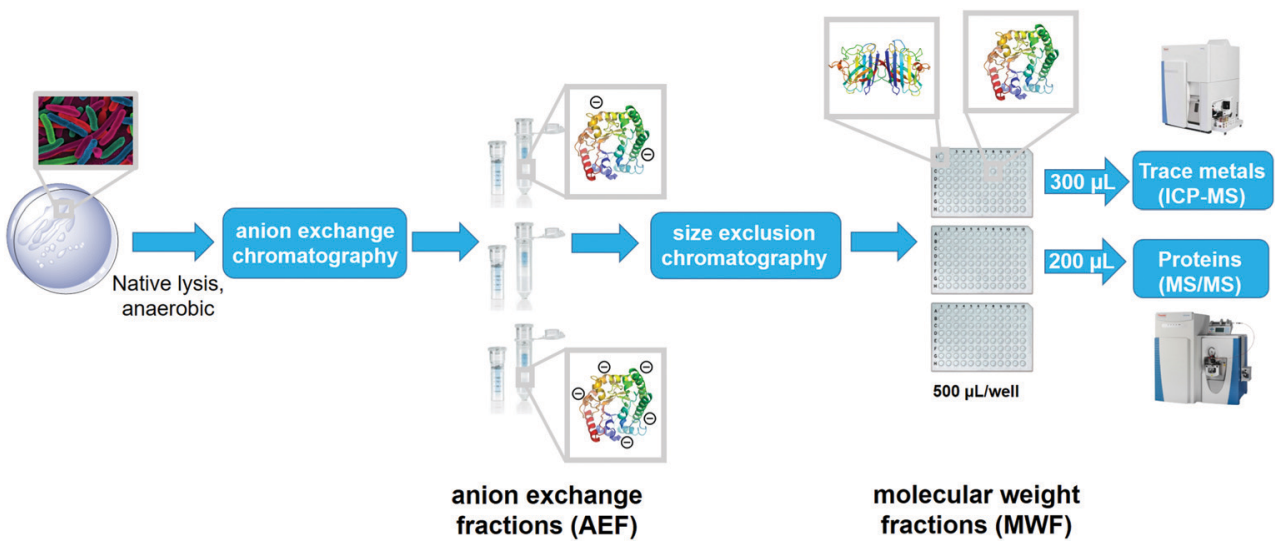

Fig. 1 The metalloproteomics pipeline, where cells are lysed under native conditions (no detergent employed), and subjected to two dimensions of chromatography: anion exchange chromatography and size exclusion chromatography. The pipeline separates a single biological sample into 384 native samples suitable for protein, metal and enzyme assay analyses. Comparison of protein and metal distributions can elucidate major metal metalloprotein reservoirs within the soluble cellular lysate. 
$23{ }^{\circ} \mathrm{C}$ for 3 hours, then streaked onto a marine agar plate with $50 \mu \mathrm{L}$ inoculum and incubated at $23{ }^{\circ} \mathrm{C}$ overnight. Pellets of BB2AT2 were grown in volume $500 \mathrm{~mL}$ of marine broth medium by inoculation at $23{ }^{\circ} \mathrm{C}$ with selection of a single colony from a marine agar plate. Growth curves were obtained with a SpectraMax $\mathrm{Me}^{5}$ unit (Molecular Devices) through absorbance measurements at $600 \mathrm{~nm}$ pipetting aliquots into a Corning clear 96 well plate at each time point. Samples were analyzed at $23{ }^{\circ} \mathrm{C}$ with a kinetic run over a period of 18 hours with a read interval of 30 minutes, with aliquots added at every timepoint. To validate this approach these plate reader growth rates were successfully intercompared with growth measurements using a Shimadzu UV-1601 spectrophotometer in a quartz cuvette $(b=1 \mathrm{~cm})$ with a $2.5 \mathrm{~mL}$ aliquot of inoculated medium (ESI $\dagger$ ). Pellets were harvested in mid-exponential phase by centrifugation at $8000 \mathrm{rpm}$ for 20 minutes using an Eppendorf $5810 \mathrm{R}$ centrifuge at $3{ }^{\circ} \mathrm{C}$, the solution was decanted, and the pellet washed with $0.2 \mu \mathrm{m}$-filtered seawater $(4 \mathrm{~mL} \times 3)$. Pellets of biomass were stored at $-80{ }^{\circ} \mathrm{C}$ until chromatographic analysis was performed.

\section{Cellular metal quota analysis}

The measured quotas reflect contributions of intracellular and extracellular metals. Biomass from triplicate $10 \mathrm{~mL}$ cultures were centrifuged at $8000 \mathrm{rpm}$ for 20 minutes at $3{ }^{\circ} \mathrm{C}$ at mid-exponential phase of growth. The cell pellet was washed by resuspension in $\sim 1 \mathrm{~mL}$ filtered seawater, transferred to an acid-cleaned microfuge tube and centrifuged again for $15 \mathrm{~min}$ at $14000 \mathrm{rpm}$ at $4{ }^{\circ} \mathrm{C}$. The whole cell pellet was digested in $800 \mu \mathrm{L}$ of $5 \%$ trace metal grade $\mathrm{HNO}_{3}$ (Optima) containing $1 \mathrm{ppb}$ Indium (In) then cells were resuspended multiple times. After digesting for 7 days at room temperature, solids were removed by centrifugation, and supernatants were collected for quota analysis. Process blank digestions containing acid, but no cells, were performed in parallel. Digests were diluted by a factor of 10 with additional $5 \%$ nitric acid (also containing $1 \mathrm{ppb}$ In), transferred to acid-washed 96 deepwell plates (Thermo Scientific) before being analyzed on an ICAP-Q inductively coupled plasma-mass spectrometer (Thermo) with an SC-4 DX FAST autosampler (Elemental Scientific, Inc.). Metal concentrations were calibrated to a multi-element standard curve (Spex, Certiprep) over a range of 1-50 ppb. Phosphorus concentrations were also measured by ICPMS and calibrated to a separate standard curve ranging from 100-1500 ppb using a stock solution of $\mathrm{Na}_{3} \mathrm{PO}_{4}$. Samples were analyzed in KED mode using helium as a collision gas after a $45 \mathrm{~s}$ sample uptake window. Mass windows were scanned 3 times during measurements. In was used to correct for variation in sample delivery and plasma suppression between samples. Blanks were subtracted from measured concentrations. Technical replicates $(n=3,3,2)$ were averaged for each biological triplicates (ESI $\dagger$ ). Averages of biological replicates and their standard deviation were then calculated. Cellular metal quota data can be accessed via https:/www.bco-dmo.org/dataset/808598.

\section{Metalloproteomic analysis}

The genome of BB2-AT2 was downloaded from NCBI, sequenced by JCVI (https://www.ncbi.nlm.nih.gov/sra/?term=BB2AT2; accessed December 11, 2019); previously classified as Alteromonas, upon
BLAST analysis more closely matches the taxon Pseudoalteromonas. For metalloproteomic analysis, all plasticware used was acid-washed unless otherwise mentioned. Buffers were prepared in Milli-Q water with Tris base (Fisher BioReagents) and $\mathrm{NaCl}$ (Sigma Aldrich, trace metal basis) with removal of extraneous metal contaminants from solution by Chelex prepared accordingly. ${ }^{50}$ The pellet of BB2-AT2 was suspended in approximately $6 \mathrm{~mL}$ of $50 \mathrm{mM}$ Tris buffer $(\mathrm{pH} 8.8)$ under anaerobic conditions $\left(<1 \mathrm{ppm}_{2}\right)$ in an $\mathrm{N}_{2}$-filled anaerobic chamber (Coy Laboratory Products Inc.) using a Fisherbrand Model 120 sonic dismembrator, sonicated for $40 \mathrm{~s}$ at $2 \mathrm{~s}$ on/off intervals while on ice. The resulting solution was then diluted to approximately $30 \mathrm{~mL}$ with additional $50 \mathrm{mM}$ Tris buffer $(\mathrm{pH} 8.8)$ and centrifuged at $4000 \mathrm{rpm}$ at $3{ }^{\circ} \mathrm{C}$ for $15-20 \mathrm{~min}$. The resulting supernatant was decanted and then purified by anion exchange chromatography using an Agilent 1100 series HPLC. A singleuse GE HiTrap Q HP anion exchange column was conditioned prior to use by washing the column with $50 \mathrm{mM}$ Tris buffer (pH 8.8) for $5 \mathrm{~min}$ at a flow rate of $1 \mathrm{~mL} \mathrm{~min}^{-1}$, then $50 \mathrm{mM}$ Tris buffer containing $1 \mathrm{M}$ sodium chloride $(\mathrm{pH} 8.8)$ for $5 \mathrm{~min}$ at a

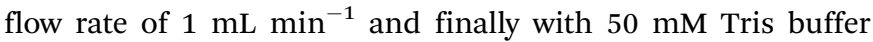
(pH 8.8) for $5 \mathrm{~min}$ at a flow rate of $1 \mathrm{~mL} \mathrm{~min}^{-1}$. The supernatant was then loaded onto the column via a $60 \mathrm{~mL}$ loading syringe onto the column using Carter $12 / 8$ cassette peristaltic pump at a rate of $0.5 \mathrm{~mL} \mathrm{~min}^{-1}$. The sample-loaded column was then connected to the Agilent HPLC system and eluted with a gradient of sodium chloride at a rate of $0.25 \mathrm{~mL} \mathrm{~min}^{-1}$. The method includes the following gradient- $50 \mathrm{mM}$ Tris buffer ( $\mathrm{pH} \mathrm{8.8)} \mathrm{for}$ 5 minutes, followed by a linear increase from $100 \% 50 \mathrm{mM}$ Tris buffer (pH 8.8) to $100 \% 50 \mathrm{mM}$ Tris buffer containing $1 \mathrm{M} \mathrm{NaCl}$ ( $\mathrm{pH}$ 8.8) over the course of $40 \mathrm{~min}$ and then $50 \mathrm{mM}$ Tris buffer $(\mathrm{pH} 8.8,1 \mathrm{M} \mathrm{NaCl})$ for $8 \mathrm{~min}$. Fractions were collected with a Bio-Rad 2110 fraction collector in $2 \mathrm{~mL}$ microtubes at a rate of 1 fraction every $4 \mathrm{~min}$, and immediately stored on ice.

Anion exchange fractions were concentrated prior to separation by size exclusion chromatography. $10 \mathrm{kDa}$ molecular weight cutoff PES Vivaspin columns were washed with $0.5 \mathrm{~mL}(\times 2)$ Tris $\mathrm{pH} 8.8$ buffer prior to use. Anion exchange fractions were loaded onto the Vivaspin columns and centrifuged at $5000 \mathrm{rpm}$ for $30 \mathrm{~min}$ using an Eppendorf MiniSpin. $0.1 \mathrm{~mL}$ of each concentrated anion exchange fraction was injected into a Michrom BioResources, Inc. HPLC system containing a Tosoh Bioscience $5 \mu \mathrm{m}$ particle size TSKgel G3000SWxl size exclusion column with guard column. Samples were eluted using an isocratic method of $50 \mathrm{mM}$ Tris buffer ( $\mathrm{pH} 7.5,50 \mathrm{mM}$ sodium chloride) at a flow rate of $0.5 \mathrm{~mL} \mathrm{~min}^{-1}$. Fractions from size exclusion chromatography were collected using a CTC Analytics HTC Pal autosampler system into an acid-washed $1.2 \mathrm{~mL}$ 96-well storage plate (Thermo Scientific), covered for storage until analysis with an acid-washed 96 cap sealing mat (Thermo Scientific).

For protein digestion, $90 \mu \mathrm{L}$ of each sample was diluted with $96 \mu \mathrm{L} 100 \mathrm{mM}$ ammonium bicarbonate solution and $10 \mu \mathrm{L}$ acetonitrile. Then $15 \mu \mathrm{L}$ of a freshly-prepared $10 \mathrm{mM}$ dithiothreitol solution was added to the samples and incubated at $70{ }^{\circ} \mathrm{C}$ for $30 \mathrm{~min}$ with shaking at $400 \mathrm{rpm}$. The samples were then allowed to cool to room temperature, and $30 \mu \mathrm{L}$ freshly-prepared $20 \mathrm{mM}$ iodoacetamide was added to each sample and allowed to incubate 
for $30 \mathrm{~min}$ in the dark. Following reduction and alkylation, $10 \mu \mathrm{L}$ of a $0.03 \mu \mathrm{g} \mu \mathrm{L}^{-1}$ trypsin stock (Promega Gold) was added to each sample and then incubated for approximately 18 hours at $37{ }^{\circ} \mathrm{C}$ with shaking at $400 \mathrm{rpm}$. Samples were then analyzed by an LC-MS on a Q-Exactive (Thermo Scientific) after separation on a C18 column following a gradient of $2-95 \%$ acetonitrile over a $90 \mathrm{~min}$ gradient using a Michrom Paradigm MG4 liquid chromatography system. Samples were ionized by electrospray with $1800 \mathrm{mV}$ potential. Proteomic analyses were used for peptide spectra matching using the SEQUEST algorithm within Proteome Discoverer (v. 2.1) and visualized in Scaffold (v. 4); protein threshold $=99.9 \%$; minimum $\#$ peptides $=2$; peptide threshold $=$ $99 \%$. All protein identifications were matched by sequence similarity to the specific hit result of BLAST search (Table 1).

Methodological comparisons were conducted in the same experimental procedure as described, however variation of the

Table 1 Exclusive unique peptides observed within the global proteomic analysis of all relevant proteins discussed in this metalloproteome. Protein threshold $=99.9 \%$; minimum \# peptides $=2$; peptide threshold $=99 \%$

\begin{tabular}{|c|c|}
\hline Protein & Exclusive unique peptides observed \\
\hline \multirow[t]{2}{*}{ Bfr 0668} & ILFLEGVPNMTK \\
\hline & IGTQNYHQAQMGE \\
\hline \multirow[t]{2}{*}{ Bfr 0669} & VLANELVGINQYFLHAR \\
\hline & ILFLEGLPNLQDLGR \\
\hline \multirow[t]{2}{*}{ SodA 2621} & LNGLIPGTEFENK \\
\hline & AVNNFGSSWTWLVK \\
\hline \multirow[t]{17}{*}{ KatG 4151} & TGQCPVMHGSNSVISK \\
\hline & VNTDWWPNTLNLDILHQHDTK \\
\hline & SNPYGTDFNYAEAFK \\
\hline & AFMTDSQDWWPADWGHYGGLMIR \\
\hline & FSPLNSWPDNASLDK \\
\hline & THGNGK \\
\hline & AEHLGPEPEAADVHEQGLGWNSTK \\
\hline & NTVTSGLEGAWTTHPT \\
\hline & SPAGAHQWEPVNIKEEDK \\
\hline & PVDVEDPSIR \\
\hline & FNDDFEYFSDVFARLAPQK \\
\hline & DWQGNEPERLANVLNALEK \\
\hline & FKAGLAK \\
\hline & PISIADLIVLGGTAAVEQAAK \\
\hline & GDFSVSPEELLLER \\
\hline & SQLMGLTAPEMTVLFGGMR \\
\hline & HGVFTDNVGTLSTDFFVNLTD \\
\hline \multirow[t]{4}{*}{ AcnB 2248} & IIQSWADAEWFTNK \\
\hline & PAVAEK \\
\hline & DGINPEK \\
\hline & PGEVGPISQLEELKAK \\
\hline \multirow[t]{6}{*}{ FrdB 2645} & YNPDVDNAPR \\
\hline & EGVCGSDGVNMNGK \\
\hline & GTIVIRPLPGLPVVR \\
\hline & VKPYLINDQPAAGER \\
\hline & FLADSRDTATEER \\
\hline & LADLDDAFSVFR \\
\hline \multirow[t]{5}{*}{ QcrA 3485} & SAGAPVEVDISKLEPGQLIR \\
\hline & LEPGQLIR \\
\hline & EHEGQLRDPQSQEPQQLESSTNDYR \\
\hline & VEGTDDGFFCPCHGSK \\
\hline & VFQSVPAPLNLEIPPYTFLDDTTILVGEEK \\
\hline \multirow{7}{*}{ Cyt1 3487} & EQLIFDGSK \\
\hline & VGGHILNAITK \\
\hline & WFGAAPPDLTNVAR \\
\hline & GSDWIYTYLK \\
\hline & VVGTETDGKGELSVDEYDQAVR \\
\hline & GELSVDEYDQAVR \\
\hline & DLTNFLEYVGEPTR \\
\hline
\end{tabular}

method of lysis was explored. For bead-beating lysis, the pellet of cellular material was suspended in $2 \mathrm{~mL}$ Tris buffer $(\mathrm{pH} 8.8)$ and approximately $100 \mu \mathrm{L}$ acid-washed glass beads $(500 \mu \mathrm{m}$, Acros Organics). The pellet was lysed by 3-30 s pulses in an anaerobic environment with a MiniBeadBeater (BioSpec Products), each followed by cooling on ice for 5 min intervals. For freezegrinding lysis, the cell pellet of was frozen under liquid nitrogen and ground into a fine powder with an acid-washed mortar and pestle. The disrupted cells were thawed under anaerobic conditions. Cytosolic metallome and metalloproteomic data can be accessed via https://www.bco-dmo.org/dataset/808610 and https://www.bcodmo.org/dataset/808619, respectively.

\section{Global metaproteomic analysis}

Marine protein samples were collected and analyzed from the METZYME expedition (KM1128) in October 2011 aboard the R/V Kilo Moana and on the ProteOMZ expedition (FK160115) on the R/V Falkor using extraction and analysis methods reported previously. ${ }^{51-54}$ While cyanobacterial functional proteins, two component regulatory systems and the nitrite oxidoreductase enzyme have been described within these metaproteomic datasets, the Pseudoalteromonas transporter described in this study has not been described. Paired metagenomic analyses were used for peptide spectra matching using the SEQUEST algorithm within Proteome Discoverer. ${ }^{51}$ Total spectral counts are displayed without normalization approaches. ${ }^{54}$ Map and protein section were prepared using Ocean Data View (version 5.0.0; Schlitzer, R., Ocean Data View, odv.awi.de, 2018) and the Ocean Protein Portal (https:// proteinportal.whoi.edu/). METATRYP software and marine microbial tryptic peptide database (https://metatryp.whoi.edu/) ${ }^{55}$ was used to query the occurrence of tryptic peptides within the protein coding sequences predicted from genomes and metagenomes.

\section{Statistical approaches: linear regressions and singular value decomposition (SVD) analysis}

Linear regressions were used to compare metalloproteome results where the metal concentration generated by ICP-MS were compared with proteomics data generated by Orbitrap LC-MS. Because multiple metalloproteins are present in the multi-dimensional dataset, subsets of data along one anion exchange fraction were used for linear regressions (e.g. comparing samples along the 600 $\mathrm{mM}$ fraction).

An approach for reconstruction of multiple major metalloproteins and the metal distributions across fractions in $2 \mathrm{D}$ space was tested using singular value decomposition (SVD). The generalized form of the data matrix can be represented as the following:

$\left[\begin{array}{cccc}{\left[\mathrm{P}_{1}\right]_{\mathrm{MWF}_{1}}} & {\left[\mathrm{P}_{2}\right]_{\mathrm{MWF}_{1}}} & {\left[\mathrm{P}_{3}\right]_{\mathrm{MWF}_{1}}} & {\left[\mathrm{P}_{n}\right]_{\mathrm{MWF}_{1}}} \\ {\left[\mathrm{P}_{1}\right]_{\mathrm{MWF}_{2}}} & {\left[\mathrm{P}_{2}\right]_{\mathrm{MWF}_{2}}} & {\left[\mathrm{P}_{3}\right]_{\mathrm{MWF}_{2}}} & {\left[\mathrm{P}_{n}\right]_{\mathrm{MWF}_{2}}} \\ {\left[\mathrm{P}_{1}\right]_{\mathrm{MWF}_{3}}} & {\left[\mathrm{P}_{2}\right]_{\mathrm{MWF}_{3}}} & {\left[\mathrm{P}_{3}\right]_{\mathrm{MWF}_{3}}} & {\left[\mathrm{P}_{n}\right]_{\mathrm{MWF}_{3}}} \\ \vdots & \vdots & \vdots & \vdots \\ {\left[\mathrm{P}_{1}\right]_{\mathrm{MWF}_{n}}} & {\left[\mathrm{P}_{2}\right]_{\mathrm{MWF}_{n}}} & {\left[\mathrm{P}_{3}\right]_{\mathrm{MWF}_{n}}} & {\left[\mathrm{P}_{n}\right]_{\mathrm{MWF}_{n}}}\end{array}\right]\left[\begin{array}{c}x_{1} \\ x_{2} \\ x_{3} \\ \vdots \\ x_{n}\end{array}\right]=\left[\begin{array}{c}{[\mathrm{M}]_{\mathrm{MWF}_{1}}} \\ {[\mathbf{M}]_{\mathrm{MWF}_{2}}} \\ {[\mathbf{M}]_{\mathrm{MWF}_{3}}} \\ \vdots \\ {[\mathbf{M}]_{\mathrm{MWF}_{n}}}\end{array}\right]$


where proteomic data can be represented as an $n \times p$ matrix, $A$, consisting of the total spectral counts of all proteins defined within metalloproteome space. The $p$ matrix, $x$, represents the proportionality constants that weight the ionization efficiencies of each proteinaceous species accordingly. The $p$ matrix, $M$, represents the concentration of Fe within the metalloproteomic space. The product of the pseudoinverse of $A$ and the $M$ fractions is defined to approximate the solution to this system of nonhomogeneous linear equations: ${ }^{56}$

$$
x \cong A^{+} M
$$

Calculation of the singular variable decomposition (SVD), gives the following reduction of the data matrix, $A$. The pseudoinverse of the protein data matrix was computed through the SVD, and the product of the resultant matrix with that of the Fe data matrix yielded the proportionality constants of each protein within the Fe metalloproteome, effectively the solution of the system of linear equations. $U$ is comprised of columns, composed by the eigenvectors of $A A^{\mathrm{T}}, D$ are the singular values, defined as the square roots of eigenvalues from $A A^{\mathrm{T}}$ or $A^{\mathrm{T}} A$, the eigenvectors of $A^{\mathrm{T}} A$ comprise the columns of $V$.

$$
A=U D V^{\mathrm{T}}
$$

where, $A^{+}=V D^{+} U^{\mathrm{T}}$

$$
x \cong V D^{+} U^{\mathrm{T}} M
$$

where the columns of $U$ and $V$ are orthonormal and the matrix, $D$, is diagonal with positive real entries.

\section{Results and Discussion}

To provide environmental context for the Pseudoalteromonas bacterium in this study, we examined the distribution of a putative TonB Fe acquisition protein attributed to the closely related Alteromonas bacterium in metaproteomic samples from the Central Equatorial Pacific Ocean (Expedition KM1128 METZYME October 2011). This expedition followed a transect from $17^{\circ} \mathrm{N}$ to $15^{\circ} \mathrm{S}$, near the Hawaiian Islands $\left(154.4^{\circ} \mathrm{W}\right)$ to the Tonga-Fiji region $\left(173.1^{\circ} \mathrm{W}\right)$. A TonB-dependent family protein with the KEGG description Fe complex outermembrane receptor protein (KEGG Orthology, KO2014) was observed in the mesopelagic of this region as depicted in Fig. 2. Taxonomic classification of specific peptides identified by metaproteomics was conducted using the METATRYP least common ancestor analysis (LCA) with all peptides being specific to either the phylum Proteobacteria, and many to the order Alteromonadales or species Alteromonas (Table 2). The chemical structure of Fe complexes used by this oceanic Alteromonas instance of the KO2014 transport system is to our knowledge not yet known, but may be siderophores. ${ }^{57,58}$ A similarity search of this KO2014 transport protein to the sequence of the ferric enterobactin receptor of BB2-AT2 (BB2AT2_1746) produced specific hits to the CirA protein family, providing additional indication that this TonB system may be responsible for siderophore uptake ( $\mathrm{ESI} \dagger)$. Metaproteomic data showed these organisms occupy a broad swath of the mesopelagic, ranging from 100-600 $\mathrm{m}$, where the exported biogenic material from the euphotic zone occurs. ${ }^{59,60}$ A maximum abundance of this Fe complex outermembrane protein was observed at the equator where increased export of organic matter arises from higher
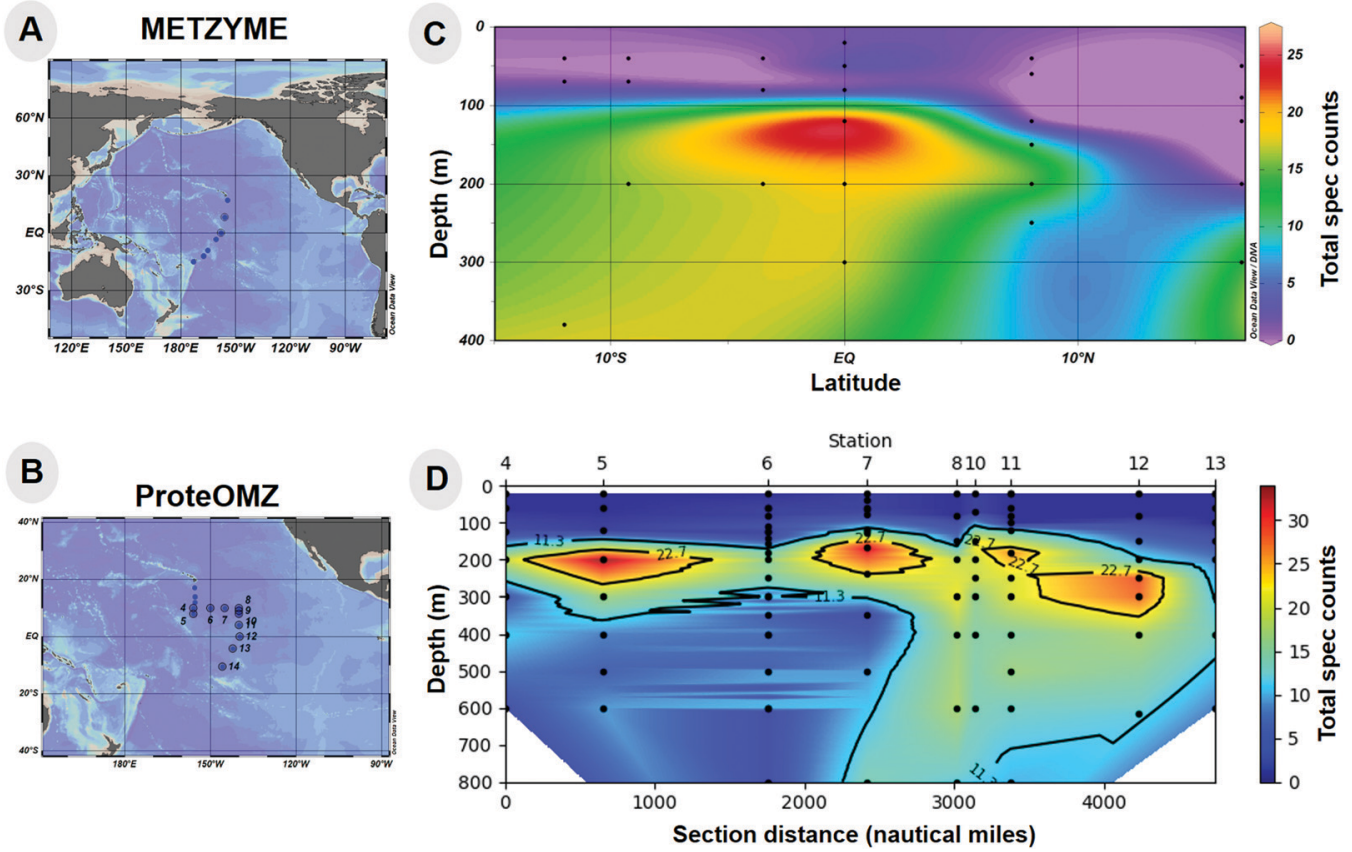

Fig. 2 Station locations for (A) METZYME (KM1128) and (B) ProteOMZ (FK160115) expeditions in the Central Pacific Ocean. Abundance (in total spectral counts) of Alteromonas TonB-dependent Fe complex outermembrane protein (KO2014) obtained from metaproteomic datasets collected on (C) METZYME (latitude on horizontal axis) and (D) ProteOMZ (distance from Station 4 on horizontal axis). Ocean sections were visualized using Ocean Data View and the Ocean Protein Portal. 
Table 2 METATRYP results of peptides for TonB-dependent Fe complex outermembrane protein (KO2014)

\begin{tabular}{lllc}
\hline Peptide & Lowest common ancestor & Genome returned & Metagenome returned \\
\hline APTPGQANISNISTVADAGGDLYQK & Alteromonadaceae & 0 & 7 \\
GTLAPTNPVSVYYGGK & Alteromonadaceae & 0 & 7 \\
GGVFSTDGGATR & Alteromonadaceae & 0 & 6 \\
LVGDVAEATAGAAR & Alteromonas & 0 & 5 \\
YEDFDTFGSTSNSK & Gammaproteobacteria & 0 & 8 \\
EEQFTVISGNK & Alteromonadaceae & 0 & 6 \\
NVLGGFFR & Undetermined & 0 & 13 \\
TCPVVPVPSGAGSSTDTALAAIK & Alteromonadaceae & 0 & 6 \\
GAVISFLGSGISDGAQGPDISAIPSIALK & Undetermined & 20 \\
DGASAQYGSDAIAGIMNFVLR & Alteromonadaceae & 0 & 8 \\
ITQGDDISITAADIALLQSLGVPGAGDLTNFR & Alteromonas & \\
ADAQGLYDGGNTAIWNYPEPAQIWGSPDVSDDYK & Alteromonadaceae & 0 & 4 \\
DNSEGTQLEIR & Alteromonas & 0 & 4 \\
& & 0 & 4
\end{tabular}

productivity associated with equatorial upwelling. These proteins were observed in the free-living bacterial size class (filter size range $0.2-3.0 \mu \mathrm{m}$ ), although it is also likely that these observations also reflect bacteria associated with fragile particles were released during filtration onto the $51 \mu \mathrm{m}$ prefilter and caught on the downstream smaller $0.2 \mu \mathrm{m}$ bacterial size during filtration. Together, these results demonstrate Alteromonas is widely distributed in the mesopelagic Pacific Ocean and produces significant quantities of putative TonB Fe complex transporter, implying cellular resources being expended on Fe acquisition.

\section{Cellular metal quota and stoichiometry of Pseudoalteromonas (BB2-AT2)}

The cellular metal quotas of Pseudoalteromonas BB2-AT2 were quantified by acid digestion of whole cells and ICP-MS analysis (Table 3). Approximately a third of the total metal abundance within this organism's metallome was devoted to Fe (31\%), and approximately half was devoted to $\mathrm{Zn} \mathrm{(48 \% ).} \mathrm{Other} \mathrm{metal}$ constituents contributed the reminder of the cellular metallome with $\mathrm{Mn}$ at $9 \%, \mathrm{Ni}$ at $6 \%, \mathrm{Cu}$ at $4 \%, \mathrm{Mo}$ at $0.6 \%$ and $\mathrm{Co}$ at $0.4 \%$.

In contrast to the cellular metal quota, the metalloproteomic separation method releases the soluble metal pools by native extraction, removal of the particulate cell debris by centrifugation, anion exchange chromatography, followed by a $10 \mathrm{kDa}$ molecular weight cutoff, size exclusion chromatography and metal analysis of the resulting supernatants. Combining the sum of these metal fractions can be used to assess the soluble metallome, relative to the total metal quota. The total and soluble metallomes were largely consistent with the exceptions of $\mathrm{Zn}$ and Ni (Table 3). The variations between the whole cell and soluble metallome likely reflects the additional contribution of metals associated with the cell surface adsorption, low molecular weight compounds below $10 \mathrm{kDa}$ and membrane proteins. $\mathrm{Zn}$ associated with membrane proteins, $<10 \mathrm{kDa}$ compounds and extracellular adsorption are likely lost during chromatographic separation The prevalence of $\mathrm{Ni}$ within the soluble metalloproteome implies presence of soluble Ni metalloproteins and minimal membrane and extracellular adsorption.

The metal stoichiometry relative to P (also measured by ICPMS) within Pseudoalteromonas was calculated for the whole cellular metallome (Table 3). In the cellular metallome, the $\mathrm{Zn}: \mathrm{P}$ ratio is the highest amongst all of these trace metal micronutrients compared, followed by Fe, Mn and Ni. Prior studies of coastal Pseudoalteromonas strains (Pseudoalteromonas sp., strain PAtl-P2) measured $\mathrm{C}: \mathrm{P}$ ratios of $\sim 51: 1,{ }^{61}$ significantly below canonical Redfield ratios of $106: 1 .^{62}$ Using this value as an estimate of the Fe:C for Pseudoalteromonas, Fe:C was estimated to be $\sim 84 \mu \mathrm{mol}: \mathrm{mol} \mathrm{Fe}: \mathrm{C}$, which is $\sim 11$ fold higher than measured in a survey of five marine bacteria $\left(7.5 \mu \mathrm{mol}: \mathrm{mol} \mathrm{Fe}: \mathrm{C}^{16,18}\right)$. Concentrations of $\mathrm{P}$ in the cytosolic metalloproteomic fractions were too low to quantitiate relative to the blank, likely reflective of the removal of the phospholipid bilayer, and hence metal: $\mathrm{P}$ values for soluble metallome were not calculated. Since this study was conducted in rich organic media compared to prior studies that used low metal concentrations in the media, the stoichiometry presented here also examines the capacity for luxury uptake into cellular storage mechanisms. To our knowledge, there is little metal stoichiometric data to compare for the other metals to for marine heterotrophic bacteria at this time.

Table 3 Comparison of cellular metal quota to that of the cytosolic metalloproteome in Pseudoalteromonas BB2-AT2. Error reflects standard deviation of biological triplicates for cellular metal quotas and three different lysis methods treated here as biological triplicates from cytosolic metalloproteome

\begin{tabular}{llllr}
\hline Metal & Cellular metal quota & Cytosolic metalloproteome & Cellular metal : P (mmol metal : mol P) & Cytosolic metal : C (mmol metal: mol C) \\
\hline $\mathrm{Fe}$ & $31.4 \pm 0.83 \%$ & $39.5 \pm 10.7 \%$ & $4.27 \pm 0.18$ & $83.8 \pm 0.61$ \\
$\mathrm{Zn}$ & $47.6 \pm 1.40 \%$ & $18.6 \pm 4.70 \%$ & $6.47 \pm 0.08$ & $126.8 \pm 1.52$ \\
$\mathrm{Mn}$ & $9.58 \pm 0.12 \%$ & $4.59 \pm 1.80 \%$ & $1.30 \pm 0.03$ & $25.5 \pm 0.61$ \\
$\mathrm{Co}$ & $0.43 \pm 0.05 \%$ & $0.32 \pm 0.02 \%$ & $0.06 \pm 0.01$ & $1.16 \pm 0.10$ \\
$\mathrm{Cu}$ & $3.71 \pm 0.12 \%$ & $1.52 \pm 2.95 \%$ & $0.50 \pm 0.01$ & $9.88 \pm 0.10$ \\
$\mathrm{Ni}$ & $6.72 \pm 0.54 \%$ & $35.0 \pm 8.37 \%$ & $0.92 \pm 0.10$ & $18.0 \pm 1.87$ \\
$\mathrm{Mo}$ & $0.57 \pm 0.03 \%$ & $0.45 \pm 0.03 \%$ & $0.08 \pm 0.02$ & $1.51 \pm 0.04$
\end{tabular}


Cytosolic Fe is localized within bacterioferritin, reactive oxygen stress mitigation and respiration proteins

The Fe metallome of Pseudoalteromonas was comprised of several abundant Fe metalloproteins including the bacterioferritin (Bfr) Fe storage protein, the reactive oxygen stress mitigation proteins, superoxide dismutase ( $\operatorname{SodA})$ and catalase (KatG), and the aconitate hydratase (AcnB), the Fe-S cluster subunit of succinate dehydrogenase (FrdB), the ubiquinol-cytochrome $c$ reductase, Fe-S subunit (QcrA) and cytochrome $c 1$ (Cyt1), all involved in respiration (Table 4).

The major reservoir of Fe within this organism was within the Fe storage proteins. Two bacterioferritin genes ( $b f r)$ are present within this organism's genome. Notably, the $b f r$ genes have distinct sequences and are localized in one operon (Fig. 3A). Proteomic analysis was able to distinguish between these Bfr protein copies (BB2AT2_0668 and BB2AT2_0669) through tryptic peptides that were unique to each copy (Fig. 3B), indicating that both copies were in active use. The distributions of Fe and Bfr protein along the $450 \mathrm{mM} \mathrm{NaCl}$ anion exchange fraction metalloproteome samples (where the majority of this protein eluted) were well correlated $\left(r^{2}\right.$ values of 0.87 and 0.91 for $\mathrm{Bfr}_{0668}$ and Bfr $_{0669}$, respectively; Fig. 3C). These proteins were observed in qualitatively equal abundance and contained the majority of cytosolic $\mathrm{Fe}$, consistent with observations of an elevated Fe cellular quota as described above. Their similar size (18 and $19 \mathrm{kDa}$ ) resulted in their elution in similar molecular weight fractions within the $450 \mathrm{mM}$ anion exchange fraction (Fig. 3D). The relatively low total spectral counts of the Bfr proteins implies a high stoichiometry of $\mathrm{Fe}$ : protein, and future targeted proteomics efforts could determine the precise stoichiometry. Bacterioferritin functions as an Fe cage, encapsulating $\mathrm{Fe}(\mathrm{OH})_{3}(\mathrm{~s})$ and minimizing the pool of labile Fe within the cell, thereby preventing Fe from forming Fenton ions and their deleterious oxidative reactions to DNA and other biomolecules. ${ }^{63}$ Pseudoalteromonas appear to bear some similarity to the pathogen, Pseudomonas aeruginosa, which also bears two distinct bacterioferritin proteins of comparable molecular weight $(\sim 18 \mathrm{kDa})$

Table 4 Summary of Fe-associated metalloproteins observed within this analysis of Pseudoalteromonas sp., BB2-AT2

\begin{tabular}{|c|c|c|c|c|c|}
\hline Gene number & Gene & Protein & Anion exchange fraction (mM NaCl) & Molecular weight fraction range & {$[\text { protein }]_{\max }$ location } \\
\hline BB2AT2_0668 & $b f r$ & Bfr & 450 & $4-8$ & 6 \\
\hline BB2AT2_0669 & bfr & Bfr & 450 & $4-8$ & 6 \\
\hline BB2AT2_2621 & $\operatorname{sod} A$ & SodA & 450 & $9-12$ & 10 \\
\hline BB2AT2_4151 & katG & KatG & 450 & $4-13$ & 8 \\
\hline BB2AT2_2248 & $a c n B$ & AcnB & $450-500$ & $4-16$ & 10 \\
\hline BB2AT2_2645 & $f r d B$ & FrdB & 450 & $4-14$ & 11 \\
\hline BB2AT2_3485 & $q \operatorname{cr} A$ & QcrA & 300 & $11-14$ & 12 \\
\hline BB2AT2_3487 & cyt1 & Cyt1 & 250 & $3-5$ & 4 \\
\hline
\end{tabular}
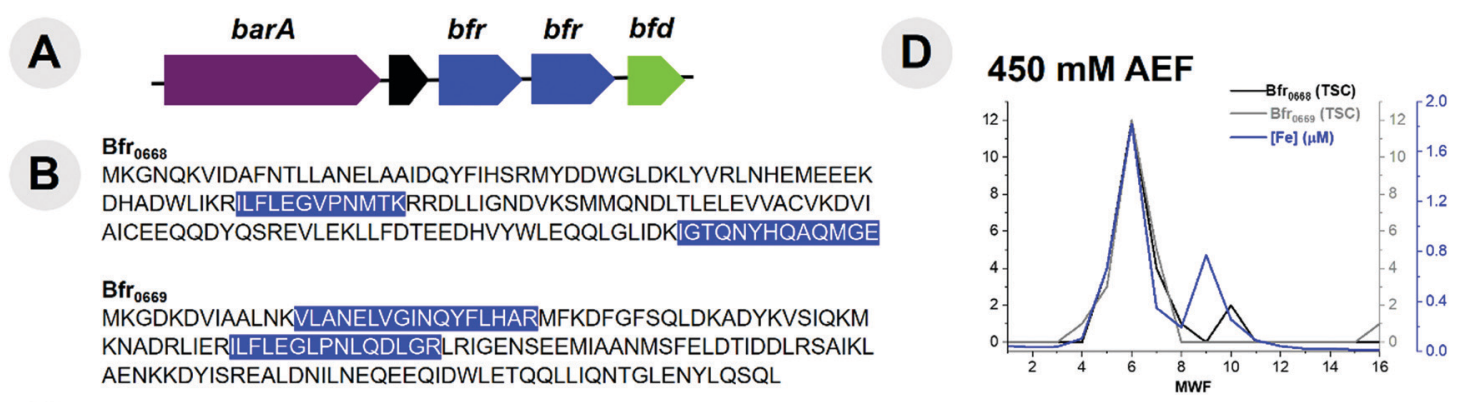

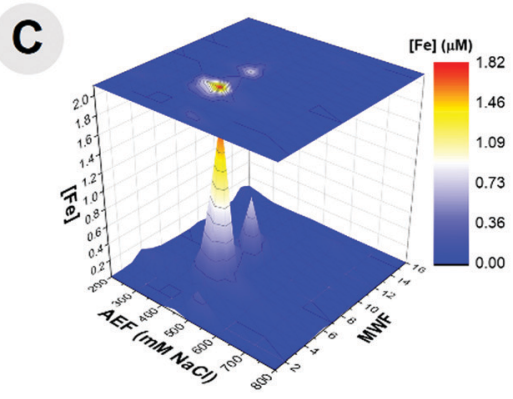

$\mathrm{Fe}$

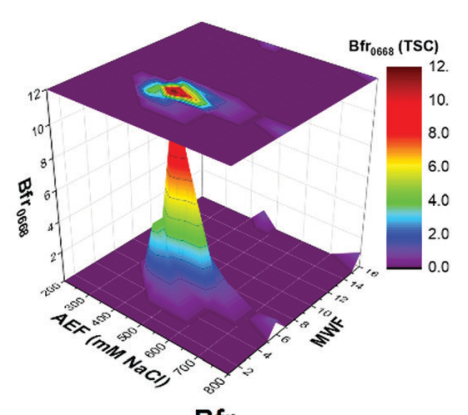

$\mathrm{Bfr}_{0668}$

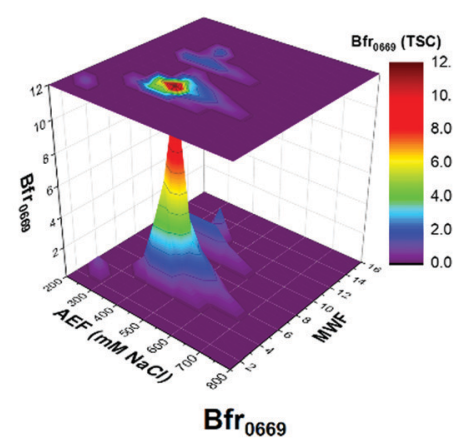

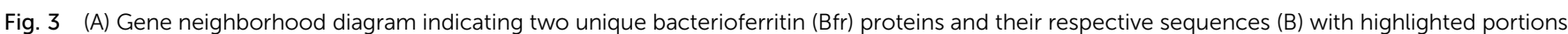

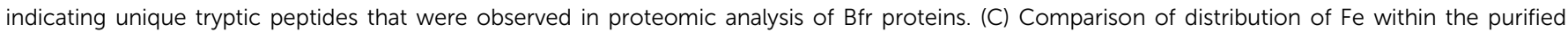

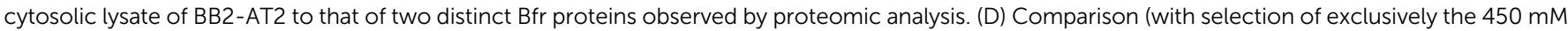

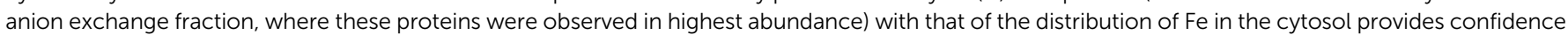
of the Fe-containing nature of these proteins. 
containing approximately $520 \pm 20 \mathrm{Fe}$ atoms per molecule of bacterioferritin. ${ }^{64}$ The gene neighborhood this pair of bacterioferritins reside in contains other potential proteins related to Fe homeostasis and regulation such as the hybrid signal transduction histidine kinase barA (BB2AT2_0666) and a hypothetical protein (BB2AT2_0667) preceded these bfr genes, but were not observed in the metalloproteome of this organism. Histidine kinases are localized to the membrane and hence were likely not extracted by the native approach used. ${ }^{65}$ Also proceeding the $b f r$ genes within the genome is a putative bacterioferritin-associated ferredoxin (BB2AT2_0670), $b f d$, which is likely a motif employed to mobilize Fe from the bacterioferritin to the cellular contents. ${ }^{66,67}$ This gene cluster and the abundance and duplication of active Bfr proteins demonstrates the importance and capabilities for $\mathrm{Fe}$ storage within the Pseudoalteromonas cellular metalloproteome.

An abundant superoxide dismutase SodA (BB2AT2_2621) from the Fe superoxide dismutase superfamily was observed with over 60 total spectral counts in the metalloproteome. In contrast, SodC (BB2AT2_1013) from the $\mathrm{Cu} / \mathrm{Zn}$ superoxide dismutase superfamily and SodN (BB2AT2_2930) in the Ni superoxide dismutase superfamily were not observed in this metalloproteomic analysis. Preferential utilization of this Fe-based SodA by BB2-AT2 is noteworthy, particularly in light of this organism's accumulation of $\mathrm{Ni}$ within the cytosol $(35.0 \pm 8.37 \%$; Table 1$)$, and may imply this microbe's preferred use of SodA under replete nutrient conditions as in our media. SodA co-elutes with both Fe and Mn within the cytosol (Fig. 4A and B). Fe and Mn superoxide dismutase isoforms are difficult to distinguish solely by sequence analysis, where the putative binding residues include His 27,
His 74, His 162, and a third residue, likely to be Asp. ${ }^{48,68}$ In BB2-AT2, the SodA has a higher degree of correlation with Fe $\left(r^{2}=0.67\right)$ than with that of $\mathrm{Mn}\left(r^{2}=0.38\right)$, and Fe is more than 10-fold more abundant than Mn at the SodA maxima (Fig. 4), implying Fe likely dominates its metal use, although the presence of co-eluting Fe-metalloenzyme KatG and AcnB peaks (see below) makes this difficult to be certain of. Additional purification and/or growth of the organism under Fe-depleted, Mn-replete conditions could further confirm the metal use within SodA.

Catalase-peroxidase, KatG, was also present as a defense mechanism against reactive oxygen stress within the metallome of Pseudoalteromonas (BB2AT2_4151). The distributions of catalaseperoxidase and Fe showed an overlap in the elution profiles. Examining the $450 \mathrm{mM}$ anion exchange fraction, where the major elution band of this protein is observed, coelution between Fe and KatG was observed (Fig. 4C). Comparison of the Fe and protein distributions along the $450 \mathrm{mM} \mathrm{NaCl}$ anion exchange fraction, where the majority of this protein eluted, reveals a correlation of $0.63\left(r^{2}\right)$ for KatG. The correlation may have been affected by the broad KatG elution profile (fractions 4-13) and its potential relationship with the smaller of two Fe peaks. Ferrochelatase, $h e m H$, an enzyme tasked with catalyzing the terminal step in the biosynthesis of heme, a critical step in the formation of a functional KatG enzyme, was present in the genome (BB2AT2_3756), however not observed in the proteome assembled from all metalloproteome samples.

Aconitate hydratase 2 (AcnB, BB2AT2_2248) is a key respiratory protein within heterotrophic bacteria and an additional metalloprotein observed to coelute with $\mathrm{Fe}$ in this study. The major
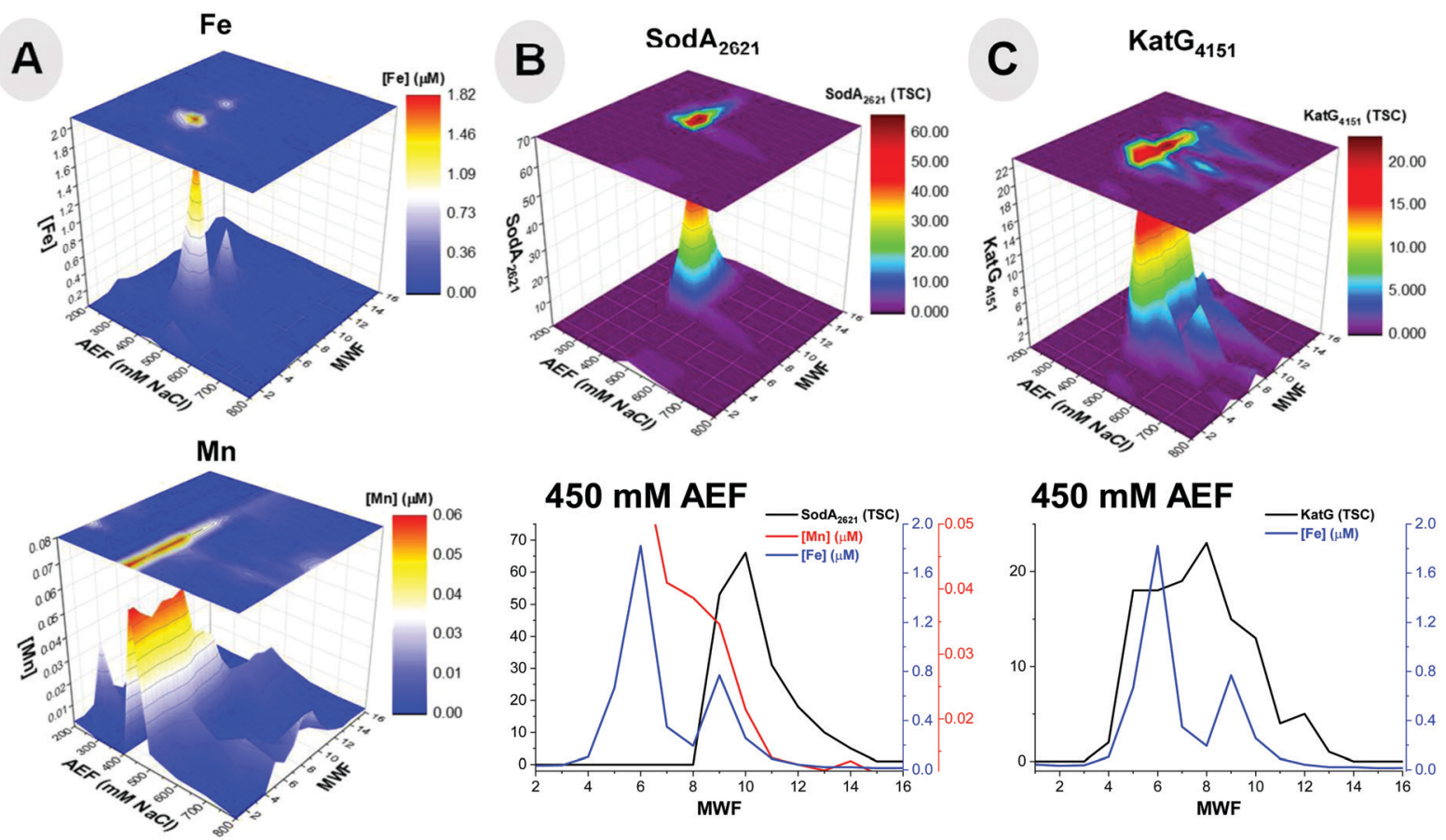

Fig. 4 The repertoire of reactive oxygen species mitigation proteins including, (A) comparison of the distributions of Fe and Mn within the purified cytosolic lysate of BB2-AT2 to that of reactive oxygen stress mitigation proteins, (B) superoxide dismutase (SodA) and (C) catalase/peroxidase (KatG) with comparison of the $450 \mathrm{mM}$ anion exchange fraction (where these proteins were observed in highest abundance) of protein and the corresponding metals. 
A $\mathrm{AcnB}_{2248}$

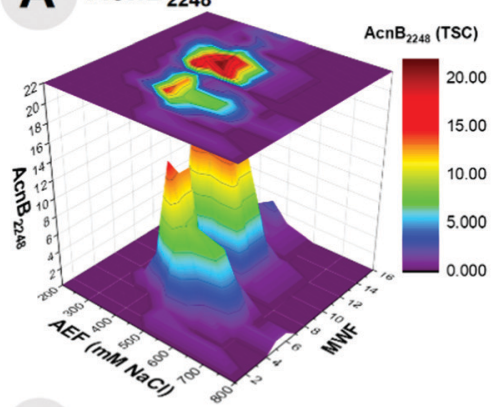

C $\operatorname{FrdB}_{264}$

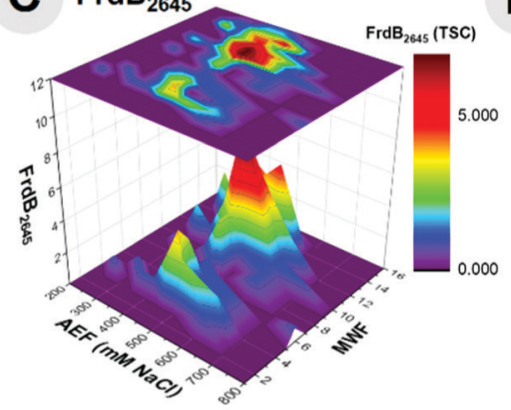

B

$450 \mathrm{mM}$ AEF

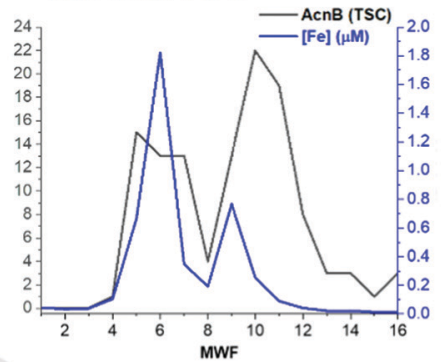

D $450 \mathrm{mM} \mathrm{AEF}$

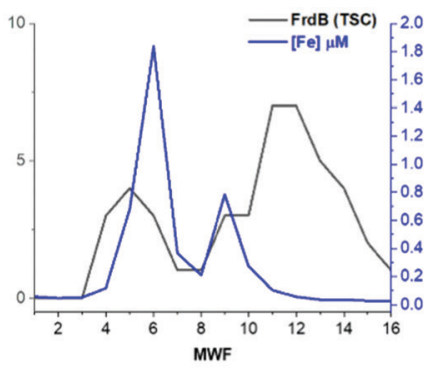

$500 \mathrm{mM}$ AEF

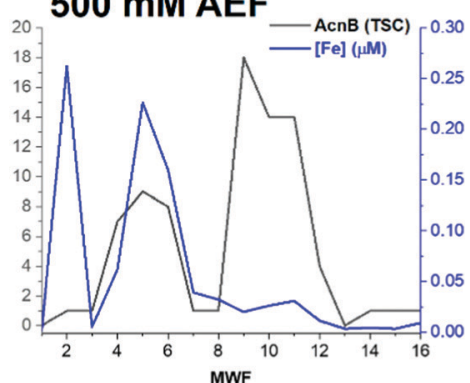

$500 \mathrm{mM}$ AEF

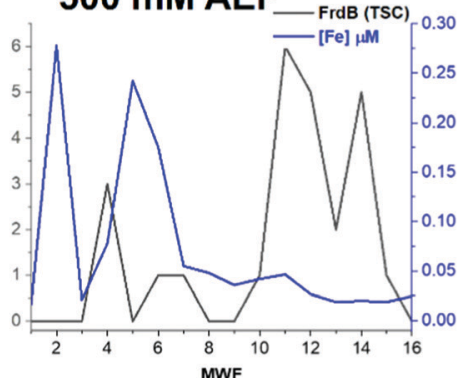

Fig. 5 (A) The distribution of aconitase (AcnB) observed within the cytosolic metalloproteome of BB2-AT2 and (B) comparison of this protein to the concentration of $\mathrm{Fe}$ within the 450 and $500 \mathrm{mM} \mathrm{NaCl}$ anion exchange fractions. (C) The distribution of the Fe-S cluster subunit of succinate dehydrogenase (FrdB) observed within the cytosolic metalloproteome of BB2-AT2 and (D) comparison of this protein to the concentration of Fe within the 450 and $500 \mathrm{mM} \mathrm{NaCl}$ anion exchange fractions.

distribution of AcnB was observed to be most abundant in the 450 and $500 \mathrm{mM} \mathrm{NaCl}$ anion exchange fractions of the metalloproteome of BB2-AT2, consistent with the substantial distribution of Fe (Fig. 5A). Upon further observation of this $450 \mathrm{mM}$ $\mathrm{NaCl}$ fraction containing the greatest abundance of AcnB, there is noteworthy overlap between these two distributions $\left(r^{2}=0.46\right.$, Fig. 5B). Comparison of the $500 \mathrm{mM} \mathrm{NaCl}$ anion exchange fraction of AcnB also yields notable overlap between the Fe and protein distributions (centered on fraction 5), and another region of minimal overlap, perhaps indicative of the apo form of this protein (centered on fraction 9-10); due to these multiple AcnB protein peaks the correlation between these metal and protein fractions at $500 \mathrm{mM} \mathrm{NaCl}$ yields minimal correlation, $r^{2}=0.11$.

The Fe-S cluster subunit of succinate dehydrogenase (FrdB, BB2AT2_2645) is a respiratory protein complex observed to coelute with Fe (Fig. 5C). Primarily localized along the 450 and $500 \mathrm{mM} \mathrm{NaCl}$ anion exchange fractions, this protein separated amongst a variety of molecular weight fractions and coelutes with both the smaller and larger Fe peaks in the $450 \mathrm{mM}$ anion exchange fraction $\left(r^{2}=0.56\right.$, Fig. 5D). Comparison of the $500 \mathrm{mM}$ $\mathrm{NaCl}$ anion exchange fraction of FrdB also yields notable overlap between the Fe and protein distributions (fraction 4, 6-7), and a region of minimal overlap (fractions 11-14), perhaps indicative of either the monomeric or apo form of this protein; the correlation between these metal and protein fractions at $500 \mathrm{mM} \mathrm{NaCl}$ yields minimal and negative correlation, $r^{2}=-0.27$, likely due to the poorly separated FrdB from the other Fe metalloproteins described above. The two Fe associated FrdB peaks in the 450 and $500 \mathrm{mM}$ fractions appeared to be shouldered under the larger signal associated with the AcnB described above, reflecting their relative contribution to the metallome.

Additional respiratory proteins within the cytochrome family of proteins, were observed within this metalloproteomic analysis; it is apparent that these peripheral membrane proteins can be stripped from the membrane easily with native lysis conditions. Three cytochrome genes ( $q c r A, q c r B$ and $c y t 1)$ are present within this organism's genome, localized within one operon (Fig. 6A). The ubiquinol-cytochrome $c$ reductase, Fe-sulfur subunit (QcrA, BB2AT2_2645), a component of the electron transport chain, was identified to coelute with the distribution of $\mathrm{Fe}$ at the $300 \mathrm{mM}$ $\mathrm{NaCl}$ anion exchange fraction (Fig. 6B). Along this $300 \mathrm{mM} \mathrm{NaCl}$ anion exchange fraction, QcrA produced an $r^{2}=0.59$. Cytochrome c1 (Cyt1, BB2AT2_3487) was also identified via metalloproteomics to coelute with $\mathrm{Fe}$, with the majority of the abundance of this protein separated along the $250 \mathrm{mM} \mathrm{NaCl}$ anion exchange fraction (Fig. 6C), with an $r^{2}=0.93$. These respiratory cytochrome proteins were well detected within the Fe metalloproteome, despite the relatively small Fe demand within each of them due to their good chromatographic separation from other major Fe proteins.

\section{Comparison of cell disruption methods}

In order to further optimize the metalloproteome methodology, we compared several methods of cell disruption, summarized in Table 5. A major concern in the analysis of metalloproteins is the denaturation and subsequent loss of metal, which would 


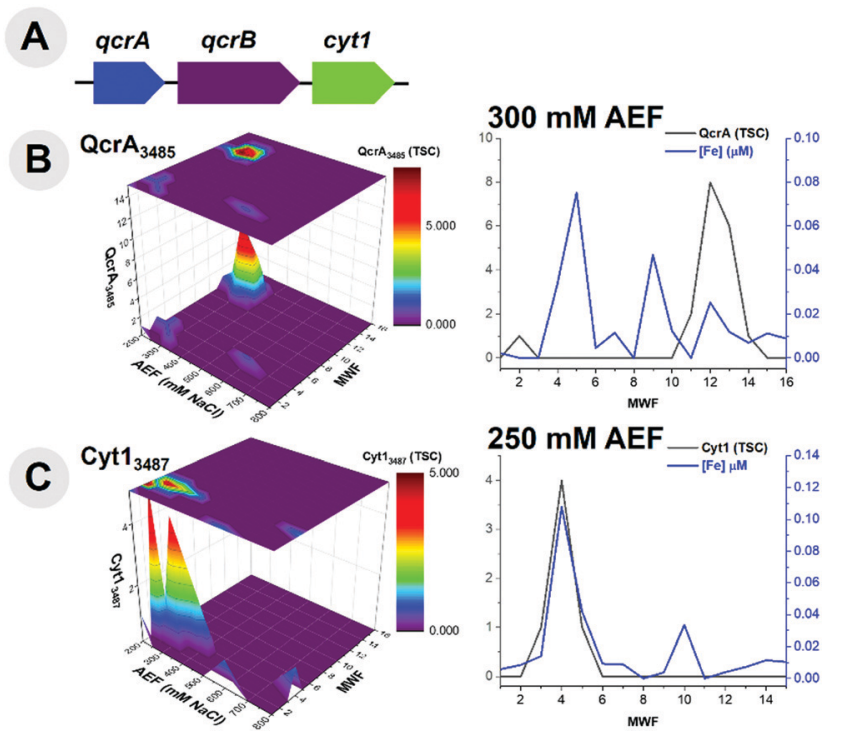

Fig. 6 (A) Gene neighborhood diagram indicating three unique cytochrome proteins and (B) comparison of the distribution of ubiquinolcytochrome $c$ reductase ( $Q \mathrm{crA}$ ) along the $300 \mathrm{mM} \mathrm{NaCl}$ anion exchange fraction. (C) The distribution of cytochrome $c 1$ (Cyt1) observed within the metalloproteome and its comparison along the $250 \mathrm{mM} \mathrm{NaCl}$ anion exchange fraction.

Table 5 Summary of Fe-associated metalloproteins observed within this analysis of Pseudoalteromonas sp., BB2-AT2

\begin{tabular}{ll}
\hline Cell disruption method & $\Sigma$ of metalloproteome proteins identified \\
\hline Sonication & 565 \\
Bead beating & 526 \\
Freeze-grinding lysis & 744
\end{tabular}

negate the ability to determine metal-protein relationships. In order to explore the potential for denaturation in future studies, we examined three methods of cell disruption: sonication, bead beating and freeze-grinding lysis. In each case, the use of detergents was avoided in order to prevent metal-protein dissociation. While sonication is performed on ice to minimize denaturation associated with heating, we were concerned about the energy input of sonication, which has the potential to shear DNA and could influence more labile metal-protein interactions. While all three methods were able to identify hundreds of soluble proteins from cultures of Pseudoalteromonas, the total number of proteins (defined here as the sum of all protein total spectral counts obtained from the entire metalloproteomic separation) obtained from freeze-grinding lysis was $>30 \%$ higher than sonication and bead beating, indicating a more effective extraction of proteins from the cell. Comparison of metalloproteomic chromatographic separation of aconitase and bacterioferritin proteins showed reasonable reproducibility, particularly for the latter although bacterioferritin is known to be heat-stable ${ }^{69}$ (Fig. 7). It is unclear why the distributions of aconitase appear somewhat different, and could be attributed to the loss of the Fe-S cluster, resulting in the apo form of this protein; the observation of a single, broad distribution of aconitase in the freeze grinding data might indicate minimal demetallation with this methodology. From this comparison, it appears all three methods are capable of producing metalloproteomes, but that freeze-grinding lysis yields a greater number of proteins, and hence could provide a more comprehensive analysis.

Singular variable decomposition analysis of metalloproteomic data

The native separation employed in this metalloproteomic method can result in metal peaks comprised of multiple metalloproteins due to overlap in their elution profiles. Peak shouldering interferes with regression analyses in the less abundant metalloprotein (or with lower metal: protein stoichiometry). As a means of computationally recreating metal profiles from protein distributions, we employed singular variable decomposition (SVD), as described in the methods. To model the relative contributions of metalloproteins to the soluble metal abundances, a low-rank data matrix from selected proteins reconstructed the distribution of Fe. Applied to the metalloproteome, the total metal concentration (in $\mu \mathrm{M}$ ), $[\mathrm{M}]$, is equal to the sum of the individual protein fractions $\left(\mathrm{P}_{1}, \mathrm{P}_{2}, \mathrm{P}_{3} \ldots \mathrm{P}_{n}\right)$, represented in total spectral counts, with a proportionality constant associated with each protein fraction $\left(x_{1}, x_{2}, x_{3} \ldots x_{n}\right)$ :

$$
[\mathrm{M}]=x_{1}\left[\mathrm{P}_{1}\right]+x_{2}\left[\mathrm{P}_{2}\right]+x_{3}\left[\mathrm{P}_{3}\right] \ldots+x_{n}\left[\mathrm{P}_{n}\right]
$$

These proportionality constants represent the aggregate ionization efficiency of peptides from each protein identified and their metal stoichiometry, and their estimation by SVD. The solution to the values of these proportionality constants is obtained by solving the nonhomogeneous system of linear equations, which can be represented in the general form,

$$
[\mathrm{M}]=[\mathrm{P}] x
$$

The data matrices, $[\mathrm{M}]$ and $[\mathrm{P}]$, have been truncated to remove edges of the dataset featuring no proteinaceous components, thus reducing the chance of spurious assignments. The following expression (eqn (3)) was written for the Fe-associated metalloproteome based on the observations described above.

$$
\begin{aligned}
& {[\mathrm{Fe}]=x_{1}\left[\operatorname{Bfr}_{0668}\right]+x_{2}\left[\operatorname{Bfr}_{0669}\right]+x_{3}\left[\operatorname{SodA}_{2621}\right]+x_{4}\left[\operatorname{KatG}_{4151}\right]} \\
& +x_{5}\left[\operatorname{AcnB}_{2248}\right]+x_{6}\left[\operatorname{Frd}_{2645}\right]+x_{7}\left[\mathrm{QcrA}_{3485}\right]+x_{8}\left[\operatorname{Cyt1}_{3487}\right]
\end{aligned}
$$

The proportionality constants $\left(x_{1}-x_{8}\right)$ were solved for using SVD and eqn (3) for 94 samples where Fe metalloproteins were observed (Table 6). Substituting the protein spectral count data into eqn (3) with the solved constants, a prediction of the $\mathrm{Fe}$ metallome from protein data was produced. A comparison of the Fe distribution from ICP-MS distribution and that of the SVD-calculated representation of the Fe distribution indicates good agreement (Fig. 8), with an $r^{2}$ of 0.84 . This method provides a quantitative assessment of the relative influence of metalloproteins to the metalloproteome of the organism, where $\mathrm{Bfr}_{0668}$ and $\mathrm{Bfr}_{0669}$ appear to majorly contribute, based on the magnitude of the singular value (Table 6), and relatively equal contributions of 38.2 and $33.6 \%$, respectively. $\mathrm{KatG}_{4151}$ appears to contribute to the Fe metalloproteome at $18.1 \%$, while $\operatorname{SodA}_{2621}$, $\mathrm{AcnB}_{2248}, \mathrm{QcrA}_{3485}, \mathrm{Cyt}_{3487}$, and $\mathrm{FrdB}_{2645}$ have minor contributions 
A sonication
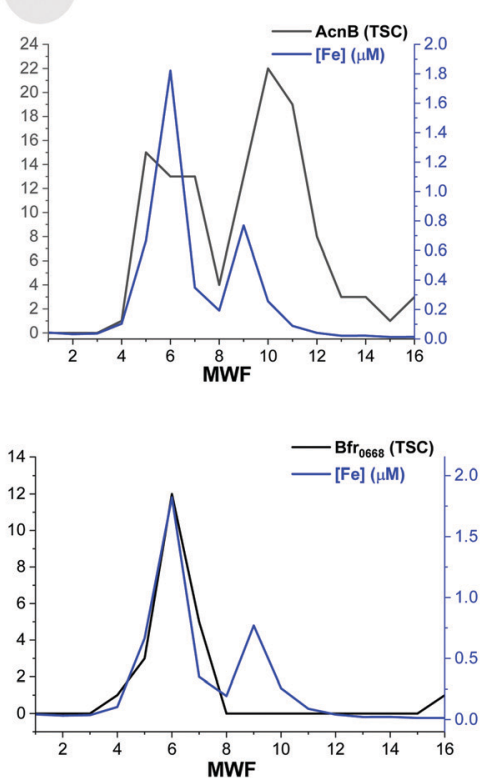

B

bead beating
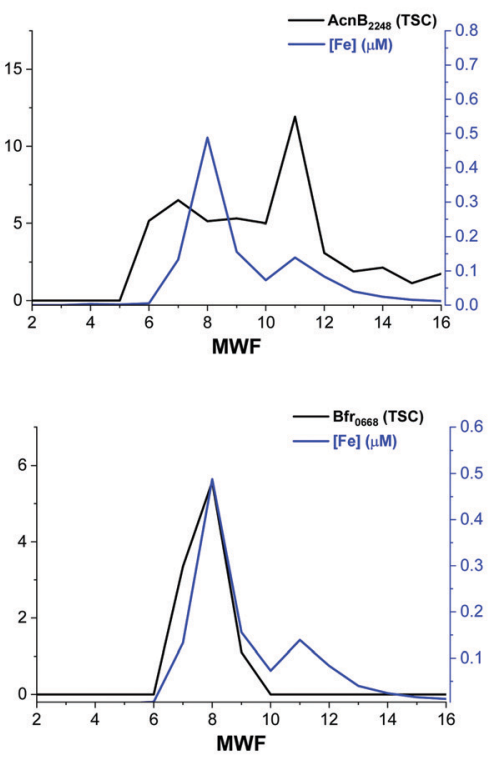

C freeze grinding
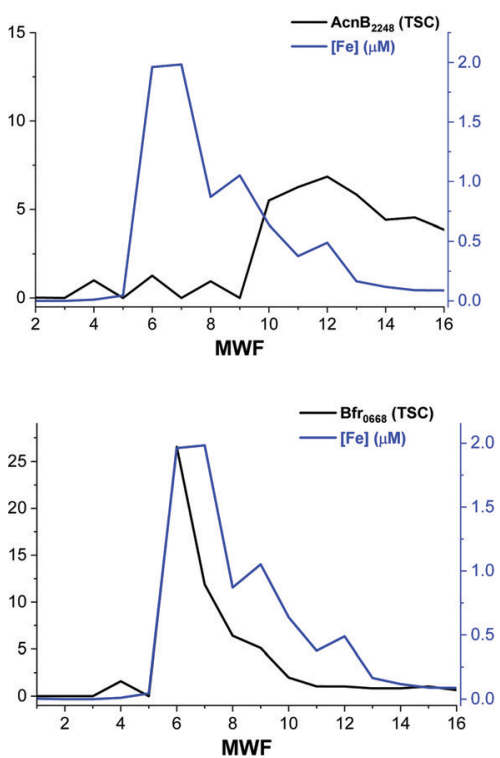

Fig. 7 Comparison of cell disruption methods within the $450 \mathrm{mM} \mathrm{NaCl}$ anion exchange fraction of the Fe metalloproteome of BB2-AT2, including the comparison of $\mathrm{AcnB}$ and $\mathrm{Bfr}_{0668}$ with (A) sonication, (B) bead beating and (C) freeze grinding.

Table 6 Protein and SVD contribution, in the form of proportionality constants for the Fe metalloproteome

\begin{tabular}{lcc}
\hline Protein & SVD contribution, $x_{n}$ & \% contribution \\
\hline $\mathrm{Bfr}_{0668}$ & 0.042 & 38.2 \\
$\mathrm{Bfr}_{0669}$ & 0.037 & 33.6 \\
SodA $_{2621}$ & 0.004 & 3.5 \\
$\mathrm{KatG}_{4151}$ & 0.020 & 18.1 \\
$\mathrm{AcnB}_{2248}$ & 0.003 & 3.2 \\
$\mathrm{FrdB}_{2645}$ & $-0.031^{a}$ & n.a. \\
QcrA $_{3485}$ & 0.0018 & 1.6 \\
Cyt1 $_{3487}$ & 0.0018 & 1.6
\end{tabular}

${ }^{a}$ FrdB returned a negative constant, likely due to its low abundance and small contribution to the metallome and was not included in the $\%$ contribution column. with $3.5,3.2,1.6,1.6 \%$ and a negative value, respectively. SVD appears to be a useful approach to modeling the major features of the metalloproteomic data from the protein total spectral counts. Future applications of SVD on cultures grown on low Fe medium to reduce the dominance of the bacterioferritins would be useful, as well as its application to other metals. ${ }^{70}$

We investigated the cellular quotas and intracellular metal reservoirs of $\mathrm{Fe}$ in the abundant marine bacterium Pseudoalteromonas grown under replete culture conditions using metalloproteomic approaches. Despite the scarcity of $\mathrm{Fe}$ in marine environments caused by the low solubility of Fe, Pseudoalteromonas demonstrated an impressive ability to accumulate and

\section{A [Fe] (ICP-MS)}

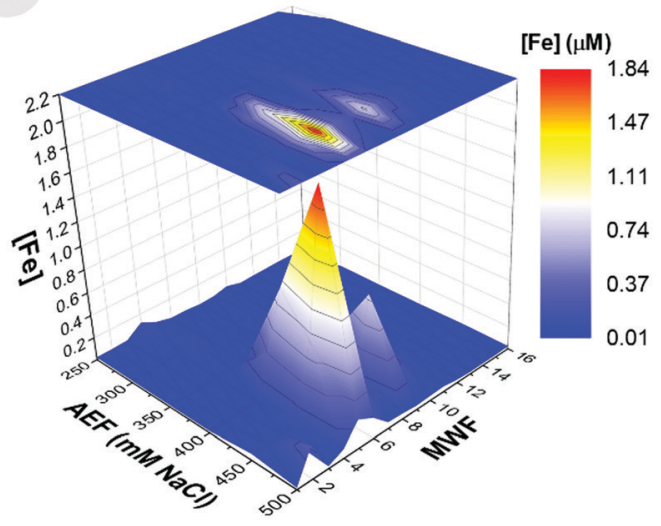

B [Fe] (SVD)

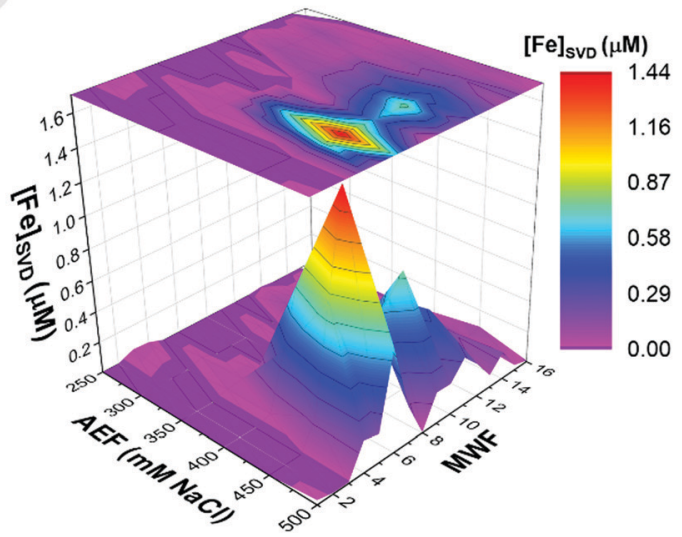

Fig. 8 Comparison of the truncated Fe distribution obtained by ICP-MS analysis (A) and the SVD-constructed data of this Fe distribution (B) indicating a good relationship between the data and model of all Fe metalloproteins within BB2-AT2, demonstrating the utility of modeling the major features of a metalloproteomic dataset. 
use Fe within its metalloproteins. These high $\mathrm{Fe}$ quotas and $\mathrm{Fe}$ metalloprotein used could reflect a dedication to Fe due to its use in the key respiratory enzyme aconitase as well as specialized abilities to acquire it from metal-rich detrital particulate material as described in Fig. 2. Future metalloproteomic studies of cultures grown on low Fe medium to reduce the dominance of the bacterioferritins and potential replacement of FeSOD would be useful to compare to these replete observations. In addition, the study of the Pseudoalteromonas metalloproteome composition with regards to other metals will be valuable. ${ }^{70}$ This study improves our understanding of the biogeochemistry of marine heterotrophic bacteria by characterizing the contribution of specific metalloproteins to the cellular Fe quota of Pseudoalteromonas and demonstrating the molecular basis for its impressive Fe storage capabilities using bacterioferritin.

\section{Conclusions}

Copiotrophs, such as the ubiquitous marine heterotroph, Pseudoalteromonas, appear well-equipped at storing Fe, showcasing an adaptation that could make them competitive for nutrient uptake relative to oligotrophs. $\mathrm{Fe}: \mathrm{C}$ in the whole cell metallome was estimated (assuming $\mathrm{C}: \mathrm{P}$ stoichiometry $\sim 51: 1$ ) to be between $\sim 83 \mu \mathrm{mol}: \mathrm{mol}$ Fe: $\mathrm{C}, \sim 11$ fold higher than prior marine bacteria surveys. This substantial Fe quota within Pseudoalteromonas was attributed to luxury uptake, mediated by two active copies of bacterioferritin proteins that together contributed $\sim 72 \%$ of the Fe metallome identified. Catalytic functions have Fe prioritized amongst a small subset of proteins devoted to destruction of reactive oxygen species, such as superoxide dismutase (SodA) and catalase/peroxidase (KatG). Fe was also observed to coelute with AcnB, consistent with its role in catalyzing the isomerization of citrate within the tricarboxylic acid cycle. FrdB, which possesses roles in both respiration and in the oxidation of succinate within the tricarboxylic acid cycle, was also found to coelute with Fe. Respiratory cytochromes (QcrA and Cyt1) were also observed within the Fe metallome Pseudoalteromonas. Three methods of cell disruption were compared for the Fe metalloproteome of BB2-AT2, including sonication, bead beating, and freeze grinding. Elution of Fe-associated proteins were relatively consistent amongst methods and the total number of proteins extracted was greatest from freeze grinding. SVD was used to model the major features of the metalloproteomic data. An Fe complex TonB transporter associated with the closely related Alteromonas bacterium was found to be abundant within the Pacific Ocean mesopelagic environment. This study improves our understanding of the biogeochemistry of marine heterotrophic bacteria by characterizing the contribution of specific metalloproteins to the cellular Fe quota of Pseudoalteromonas and demonstrating the molecular basis for its impressive Fe storage capabilities using bacterioferritin.

\section{Conflicts of interest}

There are no conflicts to declare.

\section{Acknowledgements}

M. G. M. was supported by the Camille and Henry Dreyfus Foundation Environmental Chemistry Postdoctoral Fellowship. We thank Kay Bidle (Rutgers University) for providing a culture of Pseudoalteromonas (BB2-AT2). We also thank Dawn Moran (WHOI) and Noelle Held (WHOI-MIT) for culturing assistance. We appreciate the Captain and Crew of the R/V Kilo Moana, and the many involved in the METZYME expedition sampling efforts. Discussions with Kevin Waldron (Newcastle University), Alison Butler (University of California, Santa Barbara), Lauren Manck (Scripps Institution of Oceanography), Randie Bundy (University of Washington) and Jake Gebbie (WHOI) were much appreciated. Funding for this research was provided by the Gordon and Betty Moore Foundation (3782), and NSF-OCE 1658030, 1736599, 1657766, 1924554, 1850719, 1924554.

\section{References}

1 K. W. Bruland, K. J. Orians and J. P. Cowen, Geochim. Cosmochim. Acta, 1994, 58, 3171-3182.

2 J. H. Martin and S. E. Fitzwater, Nature, 1988, 331, 341-343. 3 J. H. Martin, K. H. Coale, K. S. Johnson, S. E. Fitzwater, R. M. Gordon, S. J. Tanner, C. N. Hunter, V. A. Elrod, J. L. Nowicki, T. L. Coley, R. T. Barber, S. Lindley, A. J. Watson, K. Van Scoy, C. S. Law, M. I. Liddicoat, R. Ling, T. Stanton, J. Stockel, C. Collins, A. Anderson, R. Bidigare, M. Ondrusek, M. Latasa, F. J. Millero, K. Lee, W. Yao, J. Z. Zhang, G. Friederich, C. Sakamoto, F. Chavez, K. Buck, Z. Kolber, R. Greene, P. Falkowski, S. W. Chisholm, F. Hoge, R. Swift, J. Yungel, S. Turner, P. Nightingale, A. Hatton, P. Liss and N. W. Tindale, Nature, 1994, 371, 123-129.

4 K. H. Coale, K. S. Johnson, S. E. Fitzwater, R. M. Gordon, S. Tanner, F. P. Chavez, L. Ferioli, C. Sakamoto, P. Rogers, F. Millero, P. Steinberg, P. Nightingale, D. Cooper, W. P. Cochlan, M. R. Landry, J. Constantinou, G. Rollwagen, A. Trasvina and R. Kudela, Nature, 1996, 383, 495-501.

5 K. H. Coale, K. S. Johnson, F. P. Chavez, K. O. Buesseler, R. T. Barber, M. A. Brzezinski, W. P. Cochlan, F. J. Millero, P. G. Falkowski, J. E. Bauer, R. H. Wanninkhof, R. M. Kudela, M. A. Altabet, B. E. Hales, T. Takahashi, M. R. Landry, R. R. Bidigare, X. Wang, Z. Chase, P. G. Strutton, G. E. Friederich, M. Y. Gorbunov, V. P. Lance, A. K. Hilting, M. R. Hiscock, M. Demarest, W. T. Hiscock, K. F. Sullivan, S. J. Tanner, R. M. Gordon, C. N. Hunter, V. A. Elrod, S. E. Fitzwater, J. L. Jones, S. Tozzi, M. Koblizek, A. E. Roberts, J. Herndon, J. Brewster, N. Ladizinsky, G. Smith, D. Cooper, D. Timothy, S. L. Brown, K. E. Selph, C. C. Sheridan, B. S. Twining and Z. I. Johnson, Science, 2004, 304, 408-414.

6 D. K. Steinberg, B. A. S. V. Mooy, K. O. Buesseler, P. W. Boyd, T. Kobari and D. M. Karl, Limnol. Oceanogr., 2008, 53, 1327-1338.

7 W. G. Sunda, Front. Microbiol., 2012, 3, 204.

8 P. W. Boyd, M. J. Ellwood, A. Tagliabue and B. S. Twining, Nat. Geosci., 2017, 10, 167-173.

9 W. G. Sunda, Biol. Oceanogr., 1989, 6, 411-442. 
10 F. M. M. Morel and N. M. Price, Science, 2003, 300, 944-947. 11 J. K. Moore, S. C. Doney, D. M. Glover and I. Y. Fung, Deep Sea Res., Part II, 2001, 49, 463-507.

12 A. E. Noble, M. A. Saito, D. M. Moran and A. Allen, Front. Chem., 2013, 1, 25.

13 A. Tagliabue, A. R. Bowie, P. W. Boyd, K. N. Buck, K. S. Johnson and M. A. Saito, Nature, 2017, 543, 51-59.

14 K. J. Waldron and N. J. Robinson, Nat. Rev. Microbiol., 2009, 7, 25-35.

15 B. A. Gilston and T. V. O'Halloran, in Encyclopedia of Inorganic and Bioinorganic Chemistry, American Cancer Society, 2013, pp. 1-12.

16 P. D. Tortell, M. T. Maldonado and N. M. Price, Nature, 1996, 383, 330-332.

17 M. T. Maldonado and N. M. Price, Deep Sea Res., Part II, 1999, 46, 2447-2473.

18 P. D. Tortell, M. T. Maldonado, J. Granger and N. M. Price, FEMS Microbiol. Ecol., 1999, 29, 1-11.

19 M. A. Schmidt and D. A. Hutchins, Deep Sea Res., Part II, 1999, 46, 2487-2503.

20 P. W. Boyd, K. R. Arrigo, R. Strzepek and G. L. van Dijken, J. Geophys. Res.: Oceans, 2012, 117, C06009.

21 R. T. Reid and A. Butler, Limnol. Oceanogr., 1991, 36, 1783-1792.

22 R. T. Reid, D. H. Livet, D. J. Faulkner and A. Butler, Nature, 1993, 366, 455-458.

23 J. Granger and N. M. Price, Limnol. Oceanogr., 1999, 44, 541-555.

24 K. Barbeau, E. Kujawinski and J. Moffett, Aquat. Microb. Ecol., 2001, 24, 69-81.

25 K. Barbeau, E. L. Rue, C. G. Trick, K. W. Bruland and A. Butler, Limnol. Oceanogr., 2003, 48, 1069-1078.

26 P. D. Holt, R. R. Reid, B. L. Lewis, G. W. Luther and A. Butler, Inorg. Chem., 2005, 44, 7671-7677.

27 R. M. Bundy, M. Jiang, M. Carter and K. A. Barbeau, Front. Mar. Sci., 2016, 3, 27.

28 B. M. Hopkinson and K. A. Barbeau, Environ. Microbiol., 2012, 14, 114-128.

29 K. L. Roe, S. L. Hogle and K. A. Barbeau, Appl. Environ. Microbiol., 2013, 79, 5753-5762.

30 S. L. Hogle, J. C. Thrash, C. L. Dupont and K. A. Barbeau, Appl. Environ. Microbiol., 2016, 82, 1613-1624.

31 S. L. Hogle, R. M. Bundy, J. M. Blanton, E. E. Allen and K. A. Barbeau, Limnol. Oceanogr. Lett., 2016, 1, 36-43.

32 L. Baumann, P. Baumann, M. Mandel and R. D. Allen, J. Bacteriol., 1972, 110, 402-429.

33 J. García-Martínez, S. G. Acinas, R. Massana and F. Rodríguez-Valera, Environ. Microbiol., 2002, 4, 42-50.

34 Y. Shi, J. McCarren and E. F. DeLong, Environ. Microbiol., 2012, 14, 191-206.

35 J. McCarren, J. W. Becker, D. J. Repeta, Y. Shi, C. R. Young, R. R. Malmstrom, S. W. Chisholm and E. F. DeLong, Proc. Natl. Acad. Sci. U. S. A., 2010, 107, 16420-16427.

36 S. G. Acinas, J. Antón and F. Rodríguez-Valera, Appl. Environ. Microbiol., 1999, 65, 514-522.

37 E. Ivars-Martinez, A.-B. Martin-Cuadrado, G. D’Auria, A. Mira, S. Ferriera, J. Johnson, R. Friedman and F. RodriguezValera, ISME J., 2008, 2, 1194-1212.
38 S. Hou, M. López-Pérez, U. Pfreundt, N. Belkin, K. Stüber, B. Huettel, R. Reinhardt, I. Berman-Frank, F. RodriguezValera and W. R. Hess, ISME J., 2018, 12, 981-996.

39 A. L. Koch, BioEssays, 2001, 23, 657-661.

40 M. López-Pérez, A. Gonzaga, A.-B. Martin-Cuadrado, O. Onyshchenko, A. Ghavidel, R. Ghai and F. RodriguezValera, Sci. Rep., 2012, 2, 696.

41 K. D. Bidle and F. Azam, Nature, 1999, 397, 508-512.

42 K. D. Bidle and F. Azam, Limnol. Oceanogr., 2001, 46, 1606-1623.

43 D. C. Smith, M. Simon, A. L. Alldredge and F. Azam, Nature, 1992, 359, 139-142.

44 F. Azam and F. Malfatti, Nat. Rev. Microbiol., 2007, 5, $782-791$.

45 A. B. Burd, S. Frey, A. Cabre, T. Ito, N. M. Levine, C. Lønborg, M. Long, M. Mauritz, R. Q. Thomas, B. M. Stephens, T. Vanwalleghem and N. Zeng, Glob. Change Biol., 2016, 22, 121-136.

46 S. Tottey, K. Waldron, S. Firbank, B. Reale, C. Bessant, K. Sato, T. Cheek, J. Gray, M. Banfield, C. Dennison and N. Robinson, Nature, 2008, 455, 1138-1142.

47 A. Cvetkovic, A. L. Menon, M. P. Thorgersen, J. W. Scott, F. L. P. Ii, F. E. J. Jr, W. A. Lancaster, J. L. Praissman, S. Shanmukh, B. J. Vaccaro, S. A. Trauger, E. Kalisiak, J. V. Apon, G. Siuzdak, S. M. Yannone, J. A. Tainer and M. W. W. Adams, Nature, 2010, 466, 779-782.

48 J. D. Aguirre, H. M. Clark, M. McIlvin, C. Vazquez, S. L. Palmere, D. J. Grab, J. Seshu, P. J. Hart, M. Saito and V. C. Culotta, J. Biol. Chem., 2013, 288, 8468-8478.

49 M. D. Keller, W. K. Bellows and R. R. L. Guillard, J. Exp. Mar. Biol. Ecol., 1988, 117, 279-283.

50 N. M. Price, G. I. Harrison, J. G. Hering, R. J. Hudson, P. M. V. Nirel, B. Palenik and F. M. M. Morel, Biol. Oceanogr., 1989, 6, 443-461.

51 M. A. Saito, M. R. McIlvin, D. M. Moran, T. J. Goepfert, G. R. DiTullio, A. F. Post and C. H. Lamborg, Science, 2014, 345, 1173-1177.

52 M. A. Saito, A. Dorsk, A. F. Post, M. R. McIlvin, M. S. Rappé, G. R. DiTullio and D. M. Moran, Proteomics, 2015, 15, 3521-3531.

53 N. A. Held, M. R. McIlvin, D. M. Moran, M. T. Laub and M. A. Saito, mSystems, 2019, 4, e00317-18.

54 M. A. Saito, M. R. McIlvin, D. M. Moran, A. E. Santoro, C. L. Dupont, P. A. Rafter, J. K. Saunders, D. Kaul, C. H. Lamborg, M. Westley, F. Valois and J. B. Waterbury, Nat. Geosci., submitted.

55 M. A. Saito, A. Dorsk, A. F. Post, M. R. McIlvin, M. S. Rappé, G. R. DiTullio and D. M. Moran, Proteomics, 2015, 15, 3521-3531.

56 M. Greenberg, Differential Equations and Linear Algebra, Prentice Hall, Upper Saddle Ridge, NJ, 2001.

57 R. M. Boiteau, D. R. Mende, N. J. Hawco, M. R. McIlvin, J. N. Fitzsimmons, M. A. Saito, P. N. Sedwick, E. F. DeLong and D. J. Repeta, Proc. Natl. Acad. Sci. U. S. A., 2016, 113, 14237-14242.

58 R. M. Bundy, R. M. Boiteau, C. McLean, K. A. Turk-Kubo, M. R. McIlvin, M. A. Saito, B. A. S. Van Mooy and D. J. Repeta, Front. Mar. Sci., 2018, 5, 61. 
59 J. H. Martin, G. A. Knauer, D. M. Karl and W. W. Broenkow, Deep Sea Res., Part I, 1987, 34, 267-285.

60 A. E. Santoro, M. A. Saito, T. J. Goepfert, C. H. Lamborg, C. L. Dupont and G. R. DiTullio, Limnol. Oceanogr., 2017, 62, 1984-2003.

61 A. M. Posacka, D. M. Semeniuk and M. T. Maldonado, Front. Mar. Sci., 2019, 5, 523.

62 A. C. Redfield, B. H. Ketchum and F. A. Richards, The influence of organisms on the composition of sea water, Interscience, New York and London, 1963.

63 R. A. Floyd, Biochem. Biophys. Res. Commun., 1981, 99, 1209-1215.

64 G. R. Moore, F. H. A. Kadir, F. K. al-Massad, N. E. L. Brun, A. J. Thomson, C. Greenwood, J. N. Keen and J. B. C. Findlay, Biochem. J., 1994, 304, 493-497.
65 R. Hussain, S. E. Harding, C. S. Hughes, P. Ma, S. G. Patching, S. Edara, G. Siligardi, P. J. F. Henderson and M. K. Phillips-Jones, Biochem. Soc. Trans., 2016, 44, 810-823.

66 R. P. Garg, C. J. Vargo, X. Cui and D. M. Kurtz, Biochemistry, 1996, 35, 6297-6301.

67 Y. Wang, H. Yao, Y. Cheng, S. Lovell, K. P. Battaile, C. R. Midaugh and M. Rivera, Biochemistry, 2015, 54, 6162-6175.

68 Y. M. Garcia, A. Barwinska-Sendra, E. Tarrant, E. P. Skaar, K. J. Waldron and T. E. Kehl-Fie, PLoS Pathog., 2017, 13, e1006125.

69 S. C. Andrews, N. E. L. Brun, V. Barynin, A. J. Thomson, G. R. Moore, J. R. Guest and P. M. Harrison, J. Biol. Chem., 1995, 270, 23268-23274.

70 M. G. Mazzotta, M. R. McIlvin, D. M. Moran and M. A. Saito, in preparation. 